\title{
Senescence-Accelerated Mice P8: A Tool to Study Brain Aging and Alzheimer's Disease in a Mouse Model
}

\author{
Mercè Pallàs \\ Unitat de Farmacologia i Farmacognòosia, Facultat de Farmàcia, Institut de Biomedicina (IBUB), \\ Universitat de Barcelona y Centros de Investigación Biomédica en Red de Enfermedades Neurodegenerativas (CIBERNED), \\ Nucli Universitari de Pedralbes, 08028 Barcelona, Spain
}

Correspondence should be addressed to Mercè Pallàs, pallas@ub.edu

Received 23 September 2012; Accepted 15 October 2012

Academic Editors: A. Chiarini, E. Kolettas, and D. Scholz

Copyright (C) 2012 Mercè Pallàs. This is an open access article distributed under the Creative Commons Attribution License, which permits unrestricted use, distribution, and reproduction in any medium, provided the original work is properly cited.

\begin{abstract}
The causes of aging remain unknown, but they are probably intimately linked to a multifactorial process that affects cell networks to varying degrees. Although a growing number of aging and Alzheimer's disease (AD) animal models are available, a more comprehensive and physiological mouse model is required. In this context, the senescence-accelerated mouse prone 8 (SAMP8) has a number of advantages, since its rapid physiological senescence means that it has about half the normal lifespan of a rodent. In addition, according to data gathered over the last five years, some of its behavioral traits and histopathology resemble AD human dementia. SAMP8 has remarkable pathological similarities to $\mathrm{AD}$ and may prove to be an excellent model for acquiring more in-depth knowledge of the age-related neurodegenerative processes behind brain senescence and AD in particular. We review these facts and particularly the data on parameters related to neurodegeneration. SAMP8 also shows signs of aging in the immune, vascular, and metabolic systems, among others.
\end{abstract}

\section{Introduction to the Model: The Origin of Senescence-Accelerated Mouse Strains}

The free radical and mitochondrial theories of aging seem to be the two most prominent theories that have survived the test of time [1, 2]. These theories claim that oxidative stress within mitochondria can lead to a vicious cycle in which damaged mitochondria produce increased amounts of reactive oxygen species, leading in turn to frailty and progressive disability. If aging-associated processes result from oxidative stress, then some of the most prevalent neurodegenerative diseases associated mainly with the deleterious effects of time on cellular mechanisms can also be linked to an imbalance in the homeostatic mechanism controlling oxidative processes in the whole organism and particularly in brain [3]. The main neurodegenerative diseases are Alzheimer's (AD), Parkinson's, Huntington's, or amyotrophic lateral sclerosis [4, 5]. Of these, $\mathrm{AD}$ is the most prevalent. Many problems have had to be overcome in the last two decades of research on aging and associated neurodegenerative diseases. These include a lack of diagnostic markers or detection as well as difficulties in discovering the main molecular and cellular pathways and the causes of the deleterious effects of senescence.

In basic research, the main stumbling block has clearly been the lack of an in vivo model that naturally assimilates what happens in humans. Aging models are slow or include rare and specific mutations, such as mutated Klotho protein [6]. In the case of $\mathrm{AD}$, the models used are mice that are genetically modified by human gene insertions with the main proteins associated with $\mathrm{AD}$, that is, protein beta amyloid precursor (APP) and tau protein. We also have models in which tau kinases are overexpressed, including cyclindependent kinase 5 (cdk5) [7] or glycogen synthase kinase $3 \beta$ (GSK3 $\beta)$ [8]. However, none of the numerous animal models reliably reflect what occurs in humans. The in vitro models that are commonly used behave even worse. These include primary cultures or immortalized cell lines with or without genetic modifications, neurotoxins that undergo excitotoxic stimuli (glutamate, kainate), oxidative stress, or even treatment with amyloid $\beta(\mathrm{A} \beta)$. The aim of such 
research is to determine which molecular mechanisms are activated after these stimuli.

Senescence-accelerated mice (SAM) were originally generated from AKR/J mice by Takeda at the University of Kyoto in the early 1970s [9, 10]. After inbreeding, the observation that several litters showed features indicative of accelerated ageing, including hair loss, lordokyphosis, periophthalmic disorders, loss of activity, and shortened life expectancy, amongst other characteristics, led to selective breeding for these phenotypes using sister-brother mating. Through subsequent generations, this led the senescenceprone, short-lived inbred strain (SAMP) (mean lifespan of 9.7 months). Littermates of the age-accelerated mice that did not show senescence-related phenotypes were bred in the same fashion to obtain the senescence-resistant, long-lived mouse strain (SAMR) (mean lifespan of 16.3 months). Nine SAMP and three SAMR substrains exist, each exhibiting slightly different phenotypic abnormalities. However, the main characteristic of all SAMP strains is normal development and maturity of reproductive function, followed by an early manifestation of senescence-related phenotypes. These include neurobiological phenotypes such as deficits in learning and memory, brain atrophy, emotional disorders, abnormal circadian rhythms, and hearing impairment $[9,10]$. Most of the pathobiological phenotypes observed in SAM are age associated; their incidence and severity increase with age. Cotran et al. [11] indicated that most age-related disorders in humans can be attributed to physiological, rather than pathological, senescence. These disorders can be found in the pathobiological phenotypes in the SAM model: osteoporosis, osteoarthritis (degenerative joint disease), cataracts, hyperinflation of the lungs, and hearing impairment [11].

\section{First Steps in Characterizing SAMP8 Brain Alteration: Oxidative Disturbances}

Oxidative stress occurs when the generation of free radicals of oxygen and nitrogen exceeds the endogenous antioxidant capacity of the cells, causing neuronal death and neurodegeneration in brain. Therefore, oxidative damage is associated with ageing and neurodegenerative disorders such as $\mathrm{AD}$. The free radical theory of aging postulates that oxidative modifications by reactive oxygen species (ROS) of proteins, DNA, lipid membranes, and other molecules lead to cellular dysfunction and aging in humans and animals $[1,2]$. Physiologically, ROS are found in all aerobic organisms and arise from the secondary production of superoxide by mitochondrial reduction of molecular oxygen, the production of $\mathrm{H}_{2} \mathrm{O}_{2}$ by oxidases such as monoamine oxidase, and the reaction of superoxide with nitric oxide to yield peroxynitrite, which is capable of both oxidation and nitration reactions. The hydroxyl radical is the principal ROS implicated in biologically relevant oxidative stress and is responsible, either directly or indirectly, for most of the free radical damage seen in AD [12-16]. In mice with accelerated senescence, several of the processes associated with mitochondrial dysfunction have been shown to lead
TABLE 1: Oxidative disturbances found in SAMP8.

\begin{tabular}{lcc}
\hline Target & Modification & References \\
\hline Protein carbonylation & Increased & {$[22-25]$} \\
Lipid peroxidation & Increased & {$[22,24$,} \\
Nucleic acid oxidation & Increased & {$[25,29]$} \\
Mn SOD & Decreased activity & {$[30]$} \\
Glutathione reductase & Not modified or & {$[22,31]$} \\
& decreased activity & \\
Catalase & Not modified or & {$[22,31]$} \\
Glutamine synthetase & decreased activity & \\
NO synthase & Decreased activity & {$[24]$} \\
Accumulation of 8-oxoguanine & Increased & {$[35]$} \\
\hline
\end{tabular}

to a vicious circle with the formation of more free radicals resulting in neuronal disturbances [17-20], as shown in Table 1. The higher oxidative stress status observed in SAMP mice is partly due to mitochondrial dysfunction and may be a cause of the senescence acceleration and age-dependent alterations in cell structure and function [21].

As expected, SAMP8 exhibited higher levels of lipid peroxides and protein carbonyls than SAMR1 [22, 26]. Carbonyl modification of $\mathrm{Cu}, \mathrm{Zn}$-superoxide dismutase $(\mathrm{Cu}, \mathrm{Zn}$ $\mathrm{SOD}$ ) in liver at 3 months and hippocampal cholinergic neurostimulating peptide precursor protein (HCNP-pp) in brain at 9 months were higher in SAMP8 than in control SAMR1 [23]. Early increases in lipid peroxidation are also supported by earlier studies demonstrating that the SAMP8 shows strain-specific increases in this ROS as early as 2 months of age [27]. However, the literature on oxidative stress in SAMP8 is not always unequivocal. For example, Alvarez-Garcia et al. [22] found no differences in the activity of catalase and glutathione reductase. A different study in animals of the same age showed the opposite result: glutathione-S-transferase was not affected, but glutathione reductase and catalase were significantly inhibited compared to SAMR1 [31].

Pharmacological treatments that reduce $\mathrm{A} \beta$ (antisense to APP and antibodies to $A \beta$ ) not only improve memory but reduce oxidative stress. Early changes in lipid peroxidative damage favor mitochondrial dysfunction as a trigger for $A \beta$ overproduction in this genetically susceptible mouse strain [36]. SAMP8 fed with alpha-lipoic acid had significantly increased glutathione and decreased glutathione peroxidase and malondialdehyde, which indicated a reversal of oxidative stress, although they reported a reduction in the lifespan [37].

Oxidative processes in genomic material have also been described for SAMP8. For example, in hippocampi of old SAMP8, there were higher amounts of 8-oxoguanine (8oxo-7,8-dihydroguanine) in the RNA and lower expression of mammalian MTH1 protein, which is MutT related and catalyzes the hydrolysis of 8-oxo-7,8-dihydroguanosine triphosphate (8-oxoGTP) to monophosphate MTH1 than 
in age-matched SAMR1 [35]. Under these conditions, 8oxoguanine accumulates in the nuclear DNA in the CA1 and CA3 subregions of the hippocampus of SAMP8 in an age-dependent manner [38]. These oxidative parameters of nucleosides are also observed in the hippocampi of patients suffering from Alzheimer's disease.

\section{Genomic Approach: The Unknown World of SAMP8}

In SAMP8, there are few genetic expression studies using the array procedures and the strategies are unclear. There is wide variation in the experimental approaches, ages, organs, and brain areas that are analyzed. For these reasons, among others, clear genetic variation among SAMP8 and its putative control SAMR1 or the original strain ARJ/K was not determined until recently.

The chromosomes of the SAM strains were typed with 581 microsatellite markers amplified by PCR, and fundamental genetic information was obtained [39]. Onethird of the examined markers displayed polymorphism among the strains, and only two alleles were detected in almost all loci among the SAM and AKR/J strains. However, in 12 loci $(5.6 \%$ of the total 215 polymorphic markers), the third allele was detected among the SAM strains. A comparison of the distribution of the loci in the SAMP and SAMR series revealed notable differences in the four regions on chromosomes 4, 14, 16, and 17. This indicated that some of these chromosomal sites might contain the genes responsible for accelerated senescence in the SAMP series. An analysis in the SAM strain of microsatellite polymorphisms that explain some genetic differences can be found in http://samrc.md.shinshu-u.ac.jp/SAM_Microsatellite.htm.

Butterfield and Poon [40] demonstrated that alterations in gene expression and protein abnormalities were relevant to the age-associated learning and memory deficits in the SAMP8 strain of mice. These genes and proteins were functionally categorized into neuroprotection, signal transduction, protein folding/degradation, cytoskeleton/transport, immune response, and ROS production. All of these processes were reportedly involved in age-related cognitive decline.

Cheng and coworkers [41] used subtractive cDNA libraries containing 3136 cDNA to show that the profiles of gene expression in the hippocampus of 12-monthold SAMP8 and SAMR1 were significantly different and may play important roles in the age-related learning and memory deficit in SAMP8. In this study, of all 91 differentially expressed genes, 50 were upregulated and 41 were downregulated in the hippocampus of 12-month-old male SAMP8 compared with age-matched SAMR1. These differentially expressed genes are involved in the structures or functions of mitochondrion, purine metabolism, cell skeleton, transcription factors, the Ser/Thr family of protein kinases, the Tyr family of protein kinases, the proteintyrosine phosphatase family, the Rab family, and other signal transduction, such as MTCO1, MTCO3, UQCRFS1, Fhit, Dnchc1, kinectin, NF-L, zinc finger protein 238,
GANP, RNase H and ARNT2, CAMK2A, Map4k6-pending, ADRBK1, protein kinase raf1 and Rock1, Eph receptor B6 and Ntrk2, and RAB26. Besides the known functional genes, 38 genes without any functional clues were also identified. However, expression changes were only confirmed for six genes.

Microarray analysis in SAMP8 under treatment with a Chinese traditional preparation has been performed. They focused their analysis on the effect of the treatment, rather than the intrinsic variations between SAMP8 and its genetic control SAMR1 [42]. They reported 35 and 42 genes (in hippocampus and cortex, resp.) which vary with the treatment and validated seven genes.

Chen et al. examined frontal cortex tissue from 4- and 12-month-old SAMP8, but no comparisons were made with SAMR1 [43]. They performed a microarray with around 25,000 probe sets and expressed sequence tags. However, the analysis results were disappointing and quite limited. Only four genes were selected compared with genes reported in human aging brain.

A low-density microarray analysis was performed to analyze simultaneously the expression of some genes involved in signaling pathways related to oxidative stress, mitochondrialrelated apoptosis, cell cycle proteins, the sirtuin family, and other proteins related to neurologic diseases, cell structure, and general cell processes. In this work, 62 genes were studied and the expression levels among SAMP8 and SAMR1 were compared at different ages ( 3,6 , and 9 months). After a cross analysis, none of the 62 analyzed genes showed significant differences among $z$-scores across ages or genotype [44].

Moreover, to discover and identify the key protein biomarkers in the aging process in SAMP8 and in the control strain SAMR1, a proteomic study was reported recently [45]. The authors performed a differential proteomic analysis of hippocampus and cortex in 5- and 15-month-old SAMP8 and in control strain SAMR1. Using 2-DE combined with MALDI TOF/TOF mass spectrometry, about 1700 protein spots were isolated, and three groups of differentially expressed proteins were identified. The first group contained the strain-specific and non-age-related differential proteins that were differentially expressed in SAMP8 compared with SAMR1 mice. The changes might be implicated in the genetic difference between SAMP8 and SAMR1 mice. Specifically, the proteins ubiquitin carboxyl-terminal esterase L3, Mitofilin, adenylate kinase 4, and an unnamed protein product (gi|12847201) may be involved. The proteins in the second group were age specific and were differentially expressed between 5- and 15-month-old SAM mice. These proteins are particularly interesting, since the changes were aging related and some of them were previously reported to be expressed in $\mathrm{AD}$ patients. These proteins included $\mathrm{N}$-myc downstream-regulated gene 2, enolase 2, Cu/Zn superoxide dismutase, myosin, and two unnamed protein products (gi|74214304 and gi|74178239). The protein in the third group was SAMP8-specific age-related protein, which was identified as heme binding protein 1 . This earlier study provides new information about SAMP8-specific and agingrelated protein changes in brain. The significance of these proteins in the brain aging process and their potential roles 
as biomarkers to identify differences between SAMP8 and SAMR1 remains to be studied in depth.

\section{SAMP8 Postulated as an Early Model of Alzheimer's Disease}

While no animal model mimics exactly all of the features that are present in physiological disease or aging, the SAMP8 strain is particularly well suited to study the "transitional switch" between aging and AD as it shares many neuropathological, neurochemical, and cognitive abnormalities found in aged individuals and, to a greater extent, in patients with AD. SAMP8 presented not only similar characteristics to aged humans, such as shorter lifespan, lordosis, reduced physical activity, and hair loss [46, 47], but also some neurodegenerative features, such as early onset of learning and memory deficits [48], altered emotions and abnormal circadian rhythm [49,50], neuronal cell loss [51], and reduction in the release of neurotransmitters in the brain $[52,53]$. Besides, impairment of mitochondrial functions has been shown in SAMP8 brain at a relatively early age compared to SAMR1 mice [29]. The SAMR1 mice do not show these senescence-related neuronal phenotypes and can therefore be used as a control strain commonly.

4.1. Histopathological Similarities in SAMP8 and AD. Pathological changes in AD patients included tau hyperphosphorylation and senile plaques [54]. SAMP8 brains overproduce amyloid precursor protein (APP) and have increased phosphorylation of tau [36]. Notably, tau hyperphosphorylation increases occur as early as 5 months of age in SAMP8 $[22,55]$, which suggests that this process is an integral part of aging and, like oxidative stress, an early event in AD. Indeed, recent studies provide a more in-depth understanding of tau phosphorylation dynamics in the SAMP8. As such, the data indicates that various forms of hyperphosphorylated tau are more present in SAMP8 than in SAMR1 $[22,55]$.

Other authors have demonstrated abnormal levels of phosphorylated tau in aged (11-month-old) SAMP8 compared to SAMR1 mice [56]. Tau hyperphosphorylation in SAMP8 is mediated by AD-related mechanisms, such as increases in Cdk5 expression [55]. Moreover, treatments such as melatonin $[57,58]$ and lithium chloride [59] that reduce Cdk5 and GSK3 $\beta$ activation and activation of the cdk5/p35 pathway at its cleavage to cdk5/p25, which are all key players in $\mathrm{AD}$-related hyperphosphorylation of tau during aging and neurodegenerative diseases $[4,60]$, lead to a reduction in tau hyperphosphorylation when administered to SAMP8.

$\mathrm{A} \beta$ deposition plaques are another pathological hallmark of AD. In SAMP8, early studies using a polyclonal antibody to $A \beta_{1-42}$ [61] and $A \beta_{1-40}$ [62] showed, in comparison with control SAMR1, an age-related increase of $A \beta$ peptide that was localized in $\mathrm{AD}$-affected regions including the hippocampus [62]. Similarly, SAMP8 also shows age-related increases in $\mathrm{A} \beta \mathrm{PP}$ and mRNA [63-65]. Furthermore, cognitive deficits observed in SAMP8 were significantly improved by downregulating the expression of $\mathrm{A} \beta \mathrm{PP}$ using an antisense oligonucleotide specific to A $\beta$ PP mRNA in aged SAMP8 [64, $66]$ and oxidative stress $[67,68]$. Furthermore, other markers associated with $\mathrm{A} \beta$ dynamics and $\mathrm{AD}$ such as apolipoprotein E (ApoE) and PS2 mRNA are also altered in the SAMP8 [56].

Furthermore, SAMP8 has been considered to be a sound model for investigating the pathophysiology of the early events in $\mathrm{AD}$, due to $\mathrm{A} \beta$ accumulation $[69,70]$, cerebral amyloid angiopathy [71], brain blood barrier alterations [71-73], and different hippocampal protein aggregates [74].

The receptor for advanced glycation end product (RAGE) is a representative influx transporter of APP and $\mathrm{A} \beta$ protein in cerebral vessels, while low-density lipoprotein receptor (LDLR) and LDL-related protein 1 (LRP1) are efflux transporters. These receptors play roles not only in clearance of $\mathrm{A} \beta$ protein but also in control of oxidative stress. Wu et al. [75] found that the gene and protein expressions of RAGE were lower in SAMP8 brains than in SAMR. Moreover, LDLR levels were higher in SAMP8 brains than in SAMR1.

Recent experimental evidence in vitro and in vivo supports soluble $A \beta$ oligomers as the predominant toxic species for neurons $[76,77]$. SAMP8 shows spontaneous overproduction of soluble $A \beta$ in the hippocampus [26] and cortex [58]. Evidence strongly suggests that an increase in soluble $A \beta$ contributes to cognitive decline in aged SAMP8. It is involved in $\mathrm{AD}$ because reductions of $\mathrm{A} \beta$ using antibodies or antisense oligonucleotides improve learning and memory in these mice $[36,40,78]$. In addition, recent results using long-term green tea catechin administration prevented spatial learning and memory decline in SAMP8 by decreasing $A \beta_{1-42}$ oligomers and upregulating synapticplasticity-related proteins in the hippocampus [79].

The expression of presenilin 1 (PS1) is increased in the SAMP8 hippocampus. PS1 has been shown to play a critical role in facilitating $\gamma$-secretase activity, and levels of $\gamma$ secretase modulate the $A \beta_{42} / A \beta_{40}$ ratio, which is important for plaque formation [80]. Moreover, mutations in this protein are associated with familial AD (FAD).

Studies in APP transgenic mice have shown functional deficits and synaptic loss before the onset of $A \beta$ plaque [81] and neurofibrillary tangle formation [82]. Furthermore, several studies have characterized alterations in the dendritic spine density in mouse models of $\mathrm{AD}$, including a significant decrease in dendritic spine density in the hippocampus of the J20 and APP/PS1 mice [83] and in the CA1 subzone in $\operatorname{Tg} 2576$ and APP/Lo mice [84]. Dendritic spine state alterations have been described in SAMP8 [70].

Taken together (see Table 2), these finding suggest that abnormal expression of AD-associated genes may play a key role in the AD-like cognitive deterioration observed in the SAMP8 model.

4.2. Sirtuin 1 in SAMP8: Biochemical Coincidences in Aging and $A D$. The sirtuins are a family of NAD+-dependent deacetylases, which are highly conserved throughout evolution from yeast to eukaryotes [90]. In mammals, seven sirtuins have been described with different subcellular localizations. Their main function is deacetylating lysine residues of histones. This process is a posttranslational modification 
TABLE 2: Histopathological and cellular markers of AD and aging found in SAMP8.

\begin{tabular}{lll}
\hline Target & Modification & References \\
\hline Tau protein & $\begin{array}{l}\text { Increased levels and } \\
\text { phosphorylation } \\
\text { Increased levels or activity } \\
\text { Tau kinases }\end{array}$ & {$[22,55,56]$} \\
$\begin{array}{l}\text { Receptor for advanced } \\
\text { glycation end product }\end{array}$ & Increased & {$[22,58,59]$} \\
(RAGE) & & {$[75]$} \\
APP protein & Increased & {$[63-65,80$,} \\
& Amyloid content increased & {$[26,61,62$,} \\
B-amyloid & and aggregates & $89,70,74$, \\
& ADAM-10 and PS1 & {$[65,80,88]$} \\
Secretases & Disrupted & {$[72,73,89]$} \\
BBH & & $85,86]$ \\
\hline
\end{tabular}

that interferes with the stability and activity of the protein concerned. The deacetylation of nuclear proteins such as histones plays a critical role in gene expression regulation and chromatin silencing, in some cases allowing DNA repair [91].

Activation of sirtuin 1 (Sirt1) enables the deacetylation of a variety of proteins, resulting in a robust, protective cellular response. In this way, Sirt1 regulates many processes in mammals such as cell death, metabolism, or neurodegeneration. For example, it can deacetylate the p53 protein, which exerts antiproliferative effects and may stop growth and induce apoptosis and cellular senescence. Under stress, p53 is activated by acetylation. By deacetylating p53, Sirt1 causes it to be degraded by ubiquitination, suppressing apoptosis. By regulating the transcription factor family FoxO, Sirtl promotes survival signals. Cell death can also be inhibited by modulating the activity of $\mathrm{NF} \kappa \mathrm{B}$, a protein that can lead to apoptosis through inflammatory mechanisms. Sirt11 attenuates the expression of genes involved in the inflammatory response in the brain. These genes have increased expression in $\mathrm{AD}[92,93]$.

The correlation between aging and neurodegeneration has led researchers to investigate the sirtuin pathway as it pertains to AD. Recent reports demonstrate that Sirt1 hyperactivity can reduce $\mathrm{AD}$ pathologies both in vitro and in vivo through upregulation of the ADAM10 gene [94, 95].

Moreover, in a study with mice that overexpress the p25 protein, the activation of SIRT1 resulted in reduced levels of tau phosphorylation, accompanied by cognitive enhancement [96]. Accordingly, a decrease of SIRT1 expression with age in SAMP8 has been found [97] that correlate with a decrease in tau phosphorylation and with an increase in ADAM10 [58].

This deficiency in the neuroprotection and increase in longevity mediated by the sirtuin 1 pathway in SAMP8 neurons may contribute to the early age-related brain damage in these mice. This supports the therapeutic use of sirtuin 1enhancing agents against age-related nerve cell dysfunction and brain frailty [20].
4.3. Behavioral Characteristics. In normal aging humans and in individuals with $\mathrm{AD}$, to a more severe degree, there is deterioration in episodic memories $[98,99]$ as well as working and spatial memory $[98,99]$. Importantly, the hippocampus is also one of the most age-sensitive areas in the brain, and it is thought that the aging process greatly diminishes the plastic capabilities of this region and these declines lead to the age-related impairments in cognitive output.

SAMP8 develops age-related deficits in memory and learning. Consequently, SAMP8 has been extensively phenotyped for behavioral abnormalities. The results indicate that cognitive abnormalities in this model are abundant and the mimic behavioral/cognitive deficits observed in $\mathrm{AD}$ patients and other transgenic models [50, 100, 101]. SAMP8 also demonstrated impairment of aversive and appetitive training [101]. In SAMP8, spatial memory impairments are detected using spatial tasks such as the Morris Water Maze (MWM) and the Radial Arm Maze (RAM) beginning at approximately 4 months of age [102-104]. However, other studies suggest that spatial impairments appear earlier when more sensitive tests are used, such as the Radial Arm Water Maze (RAWM). In the RAWM, rather than in the MWM, impairments in spatial learning can be detected in SAMP8 as early as 3 months old, and the impairment in spatial memory in SAMP8 can be observed at 5 months. These results indicate that spatial learning and memory is affected in the SAMP8 early on [87].

Conversely, associative learning in the fear conditioning task is not affected in the SAMP8, but both passive and active avoidance (i.e., learning to escape by exiting the chamber in which an aversive stimulus was previously received) shows significant declines starting as early as 2 months of age [29, $105,106]$. It is interesting to note that the SAMP8 exhibits reduced anxiety-like behavior [107]. These findings, similar to those in $\mathrm{AD}$ patients and other $\mathrm{AD}$ mouse models, indicate that tasks associated with hippocampal involvement are more consistently affected in the SAMP8 than nonassociated tasks.

Del Valle et al. [70] demonstrated altered synaptic dendrite distribution and number in SAMP8 compared with SAMR1. This suggests that the learning capabilities of SAMP8 decrease, since thin spines have been related with information acquisition (learning) [108-110]. This is in agreement with the finding that SAMP8 was inefficient at resolving the object recognition test at 9 months of age.

\section{New Avenues on Molecular Changes Related to Ageing and AD in SAMP8}

5.1. Autophagy. The function of autophagy declines with aging and could determine cell and individual lifespan [111, 112]. Many neurodegenerative diseases, such as AD, Parkinson's disease, and Huntington's disease, are characterized by the formation of intracellular protein aggregates in affected brain regions, and these protein deposits are composed of ubiquitin conjugates, suggesting a failure in the protein degrading system $[111,113]$. The autophagylysosome 
pathway and ubiquitin-proteasomal system (UPS) are the main systems responsible for the digestion of most cytosolic and aggregated or misfolded proteins in brain cells [114]. The UPS selectively degrades the short-lived misfolded proteins trapped in cells [115]. In contrast, autophagy is less selective and contributes to the degradation of longlived proteins and damaged intracellular organelles (such as mitochondria) and even extracellular bodies [116]. Therefore, autophagy is fundamental for neuronal homeostasis by removing aged and prone aggregated potentially damaged proteins and providing macromolecules for further synthesis.

In SAMP8, several signs of autophagic processes have been described $[112,117]$. For example, the cathepsin D/B ratio was lower in SAMP8 than in SAMR1, which indicates dysfunction of the autophagy-lysosomal pathway.

An increase in the autophagic process was described in 10-old-month SAMP8 and related with a decrease in $\mathrm{NF} \kappa \mathrm{B}$ factor, oxidative stress, and immunodeficiency [117]. Subsequently, in the hippocampal neurons of 12-month-old SAMP8, correlated with cognitive decline in these animals, an increase in ubiquitinated proteins was described: numerous dense clumps and autophagic vacuoles were found in the cytoplasm and axons [118]. LC3-II and Beclin 1 expression showed an increase in brain areas of 7-month-old SAMP8. At 12 months, LC3-II expression remains increased whereas that of Beclin 1 was diminished. These reports suggest that autophagic activity may increase reactively at the beginning of $\mathrm{AD}$ and then decline with aging. The pathological changes of 12-month-old SAMP8 are similar to late-onset AD, from the perspective of autophagy. In addition, in spiral ganglion neurons of SAMP8, an autophagic stress process was demonstrated, with accumulation of lipofuscin inside these cells [119].

5.2. Mitochondrial Functionality in Ageing and AD. A growing body of evidence supports mitochondrial dysfunction as a prominent and early chronic oxidative stress-associated event that contributes to synaptic abnormalities in aging and, ultimately, to increased susceptibility to age-related disorders, including AD.

SAMP8 exhibits various signs of age-associated neurodegeneration, and rapid mitochondrial dysfunction, unlike SAMR1 mice [120]. The SAMP8 brain mitochondria demonstrated a higher redox state and greater activity of mitochondrial respiration with a lower respiration control ratio than the mitochondria of SAMR1 mouse brains. This indicates that an inefficient hyperactive state can exist in the mitochondrial electron transport system before ageassociated mitochondrial dysfunction develops.

Studies of aging brain mitochondria consistently report reductions in complex I activity, complex IV activity, and increased ROS production. Other age-related mitochondrial changes include reduced membrane potential and increased size. Defects in mtDNA have been found in elderly persons without $\mathrm{AD}$ and have been associated with decreased cytochrome oxidase activity in brain. The accumulation of mtDNA changes might increase ROS production and
TABLE 3: Molecular and cellular pathways altered in SAMP8.

\begin{tabular}{|c|c|c|}
\hline Pathway/protein target & Modification & Reference \\
\hline Sirtuin 1 & Decreased & {$[20,58,97]$} \\
\hline Autophagic process & Reduced & [117-119] \\
\hline Cathepsin system & Inactivated & {$[117]$} \\
\hline AMPK & Not determined & \\
\hline mTOR & Not determined & \\
\hline mtDNA damage & Increased & {$[125]$} \\
\hline $\begin{array}{l}\text { Mitochondrial electron } \\
\text { chain }\end{array}$ & Diminished efficiency & $\begin{array}{l}{[20,21,29,} \\
126,127]\end{array}$ \\
\hline Fusion/fission proteins & Not determined & \\
\hline $\begin{array}{l}\text { Mitochondrial fatty acid } \\
\text { oxidation }\end{array}$ & Altered & {$[128]$} \\
\hline
\end{tabular}

reduce mitochondrial ATP in an age-dependent manner. Increases in somatic mtDNA in aging might contribute to $\mathrm{AD}$ development (for a review, [121]).

In brain aging, mitochondrial biogenesis might represent a compensatory response to longitudinal declines in brain mitochondrial function. In $\mathrm{AD}$, data suggest that mitochondrial biogenesis picture may be mixed. There are certainly fewer normal mitochondria and more abnormal mitochondria in $\mathrm{AD}$ neurons. Mitochondrial removal via lysosomes is increased. The expression of oxidative phosphorylation subunit genes also appears mixed, with some studies showing decreased expression and others showing increased expression (at least in the intermediate stages of the disease). This raises the possibility that switching from an enhanced state to a diminished state of mitochondrial biogenesis could represent a key transition between normal brain aging and $\mathrm{AD}$. If so, then the induction of mitochondrial biogenesis should be a viable pharmacologic target for the treatment of $\mathrm{AD}$ and other neurodegenerative diseases (for a review, [122]).

In SAMP8, impairment of mitochondrial functions, including a decrease in cytochrome c oxidase (COX) activity, mitochondrial ATP content, and the mitochondrial glutathione (GSH) level, has been shown in SAMP8 brain at a relatively early age compared to SAMR1 mice [29]. In addition, significant age-dependent mitochondrial dysfunction with diminished efficiency of the electron transport chain and reduced ATP production has been found, accompanied by increased oxidative/nitrosative stress [123, 124]. Primary cultured neurons from SAMP8 showed reduced mitochondrial membrane potential and mitochondrial alterations in complexes II and IV [20]. For disturbances at a glance, see Table 3. SAMR1 mice do not show these senescencerelated phenotypes and are commonly used as a control strain.

Therefore, SAMP8 showed a mitochondrial dysfunction and frailty that partially mimics the effect of aging in this rodent. This supports the involvement of mitochondria in neuronal senescence and AD. Consequently, SAMP8 is a feasible model for developing or screening new neuroprotective molecules. 
5.3. Undetermined Pathways in SAMP8 That Could Add Value to This Senescence Mice Model: Future Perspectives. As mentioned above, alterations in Sirt1 expression have been determined in SAMP8 [97]. Sirt1 has been implicated in several cellular processes and in neurodegenerative disorders [90]. Fine-tuned positive and negative regulation of signaling networks is a critical feature of the normal, physiological signaling balance in any given cell and organelles. This is particularly evident with respect to the sirtuin 1, AMPK, and mTOR signaling pathways, which have numerous signaling attenuators and dampeners and are intrinsically related to energy balance (then mitochondrial function). Interestingly, during the aging process, the signaling intensities of these networks change in the brain. This induces brain frailty and susceptibility to the cognitive impairment that is characteristic of neurodegenerative diseases such as AD. Several recent studies have shown the functional role of AMPK in AD [129]. Vingtdeux et al. [130] demonstrated that there was abnormal accumulation of activated AMPK in tangle- and pretangle-bearing neurons in AD. AMPK signaling can regulate tau protein phosphorylation and amyloidogenesis [131]. AMPK is also a potent activator of autophagic degradation, which seems to be suppressed in AD. However, the AMPK activation responses are dependent on stimulation and the extent of activating stress. Evidently, AMPK signaling can repress and delay the appearance of AD pathology. However, later on, with increasing neuronal stress, it can trigger detrimental effects that augment AD pathogenesis.

Evidence from aged and AD brains shows that mTOR signaling is selectively increased in neurons that are likely to develop neurofibrillary tangles and that such an increase correlates with tau phosphorylation $[132,133]$. This evidence has led to the hypothesis that the chronic increase in mTOR function that occurs during aging may facilitate the development of tau pathology. Furthermore, the restoration of mTOR signaling with rapamycin reduces cognitive deficits and ameliorates $\mathrm{A} \beta$ and tau pathology by increasing autophagy.

It has also been observed that Sirt1 promotes mitochondrial biogenesis by deacetylation and activation of PGC- $1 \alpha$, a key regulator which induces the transcription of genes involved in mitochondrial biogenesis. PGC- $1 \alpha$ can also be activated by AMP-activated protein kinase (AMPK). SIRT1 activation in this case would lead to the activation of AMPK through the deacetylation of LKB1, a kinase of AMPK [134136]. However, it has been demonstrated that activation of sirtuin 1 can stimulate autophagy independently to mTOR or $\mathrm{p} 53$. Therefore, it is postulated that the proposed action of sirtuin on longevity occurs partly through cellular autophagy [137, 138].

Recent evidence suggests a parallel morphological correlation in which the balance between fission and fusion of the mitochondrial syncytia is disrupted. This could be implicated in deleterious processes within the cell, such as senescence [139]. Different stresses, such as $A \beta$, nitric oxide, rotenone, and oxidative and nitrosative stress can all shift the balance from fusion to fission (fragmentation) [140-143]. These same stresses can alter mitochondrial distribution and morphology in cells and induce severe disturbances in cell function.

Moreover, several major neurodegenerative diseasesincluding $\mathrm{AD}$, Parkinson's, and Huntington's diseaseinvolve the disruption of mitochondrial dynamics. Remarkably, in several disease models, the manipulation of mitochondrial fusion or fission can partially rescue disease phenotypes. Finally, the quality of a mitochondrial population is maintained through mitophagy, a form of autophagy in which defective mitochondria are selectively degraded (for a review, [139]).

All these deleterious effects of these age-related pathways should be studied in depth in SAMP8. This would reinforce its role as a feasible, robust model of aging, and frailty that can be used to study brain and $\mathrm{AD}$ in particular.

\section{Acknowledgments}

The author thanks the Language Advisory Service of the University of Barcelona for revising the paper. Thanks are due also to the support of Grants SAF-2009-13093, SAF2011-23631, and SAF-2012-39852 from the "Ministerio de Economia y Competitividad," 2009/SGR00893 from the "Generalitat de Catalunya," and 610RT0405 from the Programa Iberoamericano de Ciencia y Tecnologia para el Desarrollo (CYTED).

\section{References}

[1] D. Harman, "Aging: a theory based on free radical and radiation chemistry," Journal of Gerontology, vol. 11, no. 3, pp. 298-300, 1956.

[2] D. Harman, "The free radical theory of aging," Antioxidants and Redox Signaling, vol. 5, no. 5, pp. 557-561, 2003.

[3] M. A. Smith, G. Perry, P. L. Richey et al., "Oxidative damage in Alzheimer's," Nature, vol. 382, no. 6587, pp. 120-121, 1996.

[4] X. Zhu, A. K. Raina, G. Perry, and M. A. Smith, "Alzheimer's disease: the two-hit hypothesis," The Lancet Neurology, vol. 3, no. 4, pp. 219-226, 2004.

[5] X. Zhu, H. G. Lee, G. Perry, and M. A. Smith, "Alzheimer disease, the two-hit hypothesis: an update," Biochimica et Biophysica Acta, vol. 1772, no. 4, pp. 494-502, 2007.

[6] O. M. Kuro, "Klotho," Pflügers Archives European Journal of Physiology, vol. 459, no. 2, pp. 333-343, 2010.

[7] M. K. Ahlijanian, N. X. Barrezueta, R. D. Williams et al., "Hyperphosphorylated tau and neurofilament and cytoskeletal disruptions in mice overexpressing human p25, an activator of cdk5," Proceedings of the National Academy of Sciences of the United States of America, vol. 97, no. 6, pp. 2910-2915, 2000.

[8] J. Avila, E. Gómez De Barreda, T. Engel et al., "Tau kinase i overexpression induces dentate gyrus degeneration," Neurodegenerative Diseases, vol. 7, no. 1-3, pp. 13-15, 2010.

[9] T. Takeda, T. Matsushita, M. Kurozumi, K. Takemura, K. Higuchi, and M. Hosokawa, "Pathobiology of the Senescence-accelerated Mouse (SAM)," Experimental Gerontology, vol. 32, no. 1-2, pp. 117-127, 1997.

[10] T. Takeda, "Senescence-accelerated mouse (SAM): a biogerontological resource in aging research," Neurobiology of Aging, vol. 20, no. 2, pp. 105-110, 1999. 
[11] R. S. Cotran, V. Kumar, and S. L. Robbins, "Diseases of aging," in Robbins Pathologic Basis of Disease, pp. 543-551, W. B. Saunders Company, Philadelphia, Pa, USA, 1989.

[12] M. A. Smith, R. K. Kutty, P. L. Richey et al., "Heme oxygenase- 1 is associated with the neurofibrillary pathology of Alzheimer's disease," American Journal of Pathology, vol. 145, no. 1, pp. 42-47, 1994.

[13] M. A. Smith, M. Rudnicka-Nawrot, P. L. Richey et al., "Carbonyl-related posttranslational modification of neurofilament protein in the neurofibrillary pathology of Alzheimer's disease," Journal of Neurochemistry, vol. 64, no. 6, pp. 2660-2666, 1995.

[14] M. A. Smith, P. L. Richey Harris, L. M. Sayre, J. S. Beckman, and G. Perry, "Widespread peroxynitrite-mediated damage in Alzheimer's disease," Journal of Neuroscience, vol. 17, no. 8, pp. 2653-2657, 1997.

[15] G. Perry, R. J. Castellani, K. Hirai, and M. A. Smith, "Reactive oxygen species mediate cellular damage in Alzheimer disease," Journal of Alzheimer's Disease, vol. 1, no. 1, pp. 45-55, 1998.

[16] A. Nunomura, G. Perry, G. Aliev et al., "Oxidative damage is the earliest event in Alzheimer disease," Journal of Neuropathology and Experimental Neurology, vol. 60, no. 8, pp. 759-767, 2001.

[17] D. A. Butterfield, T. Koppal, B. Howard et al., "Structural and functional changes in proteins induced by free radicalmediated oxidative stress and protective action of the antioxidants N-tert-butyl- $\alpha$-phenylnitrone and vitamin E," Annals of the New York Academy of Sciences, vol. 854, pp. 448-462, 1998.

[18] A. Mori, K. Utsumi, J. Liu, and M. Hosokawa, "Oxidative damage in the senescence-accelerated mouse," Annals of the New York Academy of Sciences, vol. 854, pp. 239-250, 1998.

[19] M. Pallas, A. Camins, M. A. Smith, G. Perry, H. G. Lee, and G. Casadesus, "From aging to Alzheimer's disease: unveiling "the switch" with the senescence-accelerated mouse model (SAMP8)," Journal of Alzheimer's Disease, vol. 15, no. 4, pp. 615-624, 2008.

[20] R. Cristòfol, D. Porquet, R. Corpas et al., "Neurons from senescence-accelerated SAMP8 mice are protected against frailty by the sirtuin 1 promoting agents melatonin and resveratrol," Journal of Pineal Research, vol. 52, no. 3, pp. 271281, 2012.

[21] Y. Chiba, A. Shimada, N. Kumagai et al., "The senescenceaccelerated mouse (SAM): a higher oxidative stress and age-dependent degenerative diseases model," Neurochemical Research, vol. 34, no. 4, pp. 679-687, 2009.

[22] O. Alvarez-García, I. Vega-Naredo, V. Sierra et al., "Elevated oxidative stress in the brain of senescence-accelerated mice at 5 months of age," Biogerontology, vol. 7, no. 1, pp. 43-52, 2006.

[23] H. Nabeshi, S. Oikawa, S. Inoue, K. Nishino, and S. Kawanishi, "Proteomic analysis for protein carbonyl as an indicator of oxidative damage in senescence-accelerated mice," Free Radical Research, vol. 40, no. 11, pp. 1173-1181, 2006.

[24] B. Bayram, S. Nikolai, P. Huebbe et al., "Biomarkers of oxidative stress, antioxidant defence and inflammation are altered in the senescence-accelerated mouse prone 8," Age. In press.

[25] W. Gan, B. Nie, F. Shi et al., "Age-dependent increases in the oxidative damage of DNA, RNA, and their metabolites in normal and senescence-accelerated mice analyzed by LCMS/MS: urinary 8-oxoguanosine as a novel biomarker of aging," Free Radical Biology Medicine, vol. 52, no. 9, pp. 17001707, 2012.

[26] A. L. Petursdottir, S. A. Farr, J. E. Morley, W. A. Banks, and G. V. Skuladottir, "Lipid peroxidation in brain during aging in the senescence-accelerated mouse (SAM)," Neurobiology of Aging, vol. 28, no. 8, pp. 1170-1178, 2007.

[27] F. Yasui, M. Ishibashi, S. Matsugo, S. Kojo, Y. Oomura, and K. Sasaki, "Brain lipid hydroperoxide level increases in senescence-accelerated mice at an early age," Neuroscience Letters, vol. 350, no. 1, pp. 66-68, 2003.

[28] D. A. Butterfield, B. J. Howard, S. Yatin, K. L. Allen, and J. M. Carney, "Free radical oxidation of brain proteins in accelerated senescence and its modulation by N-tert-butyl$\alpha$-phenylnitrone," Proceedings of the National Academy of Sciences of the United States of America, vol. 94, no. 2, pp. 674678, 1997.

[29] C. Shi, S. Xiao, J. Liu et al., "Ginkgo biloba extract EGb761 protects against aging-associated mitochondrial dysfunction in platelets and hippocampi of SAMP8 mice," Platelets, vol. 21, no. 5, pp. 373-379, 2010.

[30] T. Kurokawa, S. Asada, S. Nishitani, and O. Hazeki, "Agerelated changes in manganese superoxide dismutase activity in the cerebral cortex of senescence-accelerated prone and resistant mouse," Neuroscience Letters, vol. 298, no. 2, pp. 135-138, 2001.

[31] F. X. Sureda, J. Gutierrez-Cuesta, M. Romeu et al., "Changes in oxidative stress parameters and neurodegeneration markers in the brain of the senescence-accelerated mice SAMP-8," Experimental Gerontology, vol. 41, no. 4, pp. 360-367, 2006.

[32] A. K. Ali, W. A. Banks, V. B. Kumar et al., "Nitric oxide activity and isoenzyme expression in the senescence- accelerated mouse P8 model of Alzheimer's disease: effects of anti-amyloid antibody and antisense treatments," Journals of Gerontology, vol. 64, no. 10, pp. 1025-1030, 2009.

[33] D. Colas, A. Gharib, L. Bezin et al., "Regional age-related changes in neuronal nitric oxide synthase (nNOS), messenger RNA levels and activity in SAMP8 brain," BMC Neuroscience, vol. 7, article 81, 2006.

[34] D. Acuña-Castroviejo, M. Carretero, C. Doerrier et al., "Melatonin protects lung mitochondria from aging," Age, vol. 34, no. 3, pp. 681-692, 2012.

[35] X. N. Song, L. Q. Zhang, D. G. Liu et al., "Oxidative damage to RNA and expression patterns of MTH1 in the hippocampi of senescence-accelerated SAMP8 mice and Alzheimer's disease patients," Neurochemical Research, vol. 36, no. 8, pp. 1558-1565, 2011.

[36] J. E. Morley, H. J. Armbrecht, S. A. Farr et al., "The senescence accelerated mouse (SAMP8) as a model for oxidative stress and Alzheimer's disease," Biochimica and Biophysica Acta, vol. 1822, no. 5, pp. 650-656, 2012.

[37] S. A. Farr, T. O. Price, W. A. Banks et al., "Effect of alphalipoic acid on memory, oxidation, and lifespan in SAMP8 mice," Journal of Alzheimer's Disease, vol. 32, no. 2, pp. 447455, 2012.

[38] J. D. Zheng, A. L. Hei, P. P. Zuo et al., "Age-related alterations in the expression of MTH2 in the hippocampus of the SAMP8 mouse with learning and memory deterioration," Journal of the Neurological Sciences, vol. 287, no. 1-2, pp. 188196, 2009.

[39] C. Xia, K. Higuchi, M. Shimizu et al., "Genetic typing of the Senescence-accelerated mouse (SAM) strains with microsatellite markers," Mammalian Genome, vol. 10, no. 3, pp. 235-238, 1999. 
[40] D. A. Butterfield and H. F. Poon, "The senescence-accelerated prone mouse (SAMP8): a model of age-related cognitive decline with relevance to alterations of the gene expression and protein abnormalities in Alzheimer's disease," Experimental Gerontology, vol. 40, no. 10, pp. 774-783, 2005.

[41] X. R. Cheng, W. X. Zhou, Y. X. Zhang, D. S. Zhou, R. F. Yang, and L. F. Chen, "Differential gene expression profiles in the hippocampus of senescence-accelerated mouse," Neurobiology of Aging, vol. 28, no. 4, pp. 497-506, 2007.

[42] Y. Zheng, X. R. Cheng, W. X. Zhou, and Y. X. Zhang, "Gene expression patterns of hippocampus and cerebral cortex of senescence-accelerated mouse treated with Huang-Lian-JieDu decoction," Neuroscience Letters, vol. 439, no. 2, pp. 119124, 2008.

[43] S. C. Chen, G. Lu, C. Y. Chan et al., "Microarray profile of brain aging-related genes in the frontal cortex of SAMP8," Journal of Molecular Neuroscience, vol. 41, no. 1, pp. 12-16, 2010.

[44] G. Casadesus, J. Gutierrez-Cuesta, and H. G. Lee, "Neuronal cell cycle re-entry markers are altered in the senescence accelerated mouse P8 (SAMP8)," Journal of Alzheimer's disease, vol. 30, no. 3, pp. 573-583, 2012.

[45] L. Zhu, J. Yu, Q. Shi et al., "Strain-and age-related alteration of proteins in the brain of SAMP8 and SAMR1 mice," Journal of Alzheimer's Disease, vol. 23, no. 4, pp. 641-654, 2011.

[46] M. Hosokawa, R. Kasai, K. Higuchi et al., "Grading score system: a method for evaluation of the degree of senescence in senescence accelerated mouse (SAM)," Mechanisms of Ageing and Development, vol. 26, no. 1, pp. 91-102, 1984.

[47] T. Takeda, M. Hosokawa, K. Higuchi, M. Hosono, I. Akiguchi, and H. Katoh, "A novel murine model of aging, Senescence-accelerated mouse (SAM)," Archives of Gerontology and Geriatrics, vol. 19, no. 2, pp. 185-192, 1994.

[48] J. C. López-Ramos, M. T. Jurado-Parras, C. Sanfeliu, D. Acuña-Castroviejo, and J. M. Delgado-García, "Learning capabilities and CA1-prefrontal synaptic plasticity in a mice model of accelerated senescence," Neurobiology of Aging, vol. 33, no. 3, pp. 627.e13-627.e26, 2011.

[49] M. Miyamoto, "Characteristics of age-related behavioral changes in senescence-accelerated Mouse SAMP8 and SAMP10," Experimental Gerontology, vol. 32, no. 1-2, pp. 139-148, 1997.

[50] M. Miyamoto, Y. Kiyota, N. Yamazaki et al., "Age-related changes in learning and memory in the senescenceaccelerated mouse (SAM)," Physiology and Behavior, vol. 38, no. 3, pp. 399-406, 1986.

[51] T. Kawamata, I. Akiguchi, H. Yagi et al., "Neuropathological studies on strains of senescence-accelerated mice (SAM) with age-related deficits in learning and memory," Experimental Gerontology, vol. 32, no. 1-2, pp. 161-169, 1997.

[52] X. H. Zhao and Y. Nomura, "Age-related changes in uptake and release on $\mathrm{L}-\left[{ }^{3} \mathrm{H}\right]$ noradrenaline in brain slices of senescence accelerated mouse," International Journal of Developmental Neuroscience, vol. 8, no. 3, pp. 267-272, 1990.

[53] Y. Kitamura, X. H. Zhao, T. Ohnuki, M. Takei, and Y. Nomura, "Age-related changes in transmitter glutamate and NMDA receptor/channels in the brain of senescenceaccelerated mouse," Neuroscience Letters, vol. 137, no. 2, pp. 169-172, 1992.

[54] D. J. Selkoe, "Amyloid $\beta$-protein and the genetics of Alzheimer's disease," Journal of Biological Chemistry, vol. 271, no. 31, pp. 18295-18298, 1996.

[55] A. M. Canudas, J. Gutierrez-Cuesta, M. I. Rodríguez et al., "Hyperphosphorylation of microtubule-associated protein tau in senescence-accelerated mouse (SAM)," Mechanisms of Ageing and Development, vol. 126, no. 12, pp. 1300-1304, 2005.

[56] X. Wei, Y. Zhang, and J. Zhou, “Alzheimer's disease-related gene expression in the brain of senescence accelerated mouse," Neuroscience Letters, vol. 268, no. 3, pp. 139-142, 1999.

[57] J. Gutierrez-Cuesta, F. X. Sureda, M. Romeu et al., "Chronic administration of melatonin reduces cerebral injury biomarkers in SAMP8," Journal of Pineal Research, vol. 42, no. 4, pp. 394-402, 2007.

[58] J. Gutierrez-Cuesta, M. Tajes, A. Jiménez, A. Coto-Montes, A. Camins, and M. Pallàs, "Evaluation of potential pro-survival pathways regulated by melatonin in a murine senescence model," Journal of Pineal Research, vol. 45, no. 4, pp. 497-505, 2008.

[59] M. Tajes, J. Gutierrez-Cuesta, J. Folch et al., "Lithium treatment decreases activities of tau kinases in a murine model of senescence," Journal of Neuropathology and Experimental Neurology, vol. 67, no. 6, pp. 612-623, 2008.

[60] M. Hamdane, P. Delobel, A. V. Sambo et al., "Neurofibrillary degeneration of the Alzheimer-type: an alternate pathway to neuronal apoptosis?" Biochemical Pharmacology, vol. 66, no. 8, pp. 1619-1625, 2003.

[61] M. Takemura, S. Nakamura, I. Akiguchi et al., " $\beta / A 4$ proteinlike immunoreactive granular structures in the brain of senescence-accelerated mouse," American Journal of Pathology, vol. 142, no. 6, pp. 1887-1897, 1993.

[62] A. Fukunari, A. Kato, Y. Sakai et al., "Colocalization of prolyl endopeptidase and amyloid $\beta$-peptide in brains of senescence-accelerated mouse," Neuroscience Letters, vol. 176, no. 2, pp. 201-204, 1994.

[63] Y. Nomura, Y. Yamanaka, Y. Kitamura et al., "Senescenceaccelerated mouse: neurochemical studies on aging," Annals of the New York Academy of Sciences, vol. 786, pp. 410-418, 1996.

[64] V. B. Kumar, M. W. Franko, S. A. Farr, H. J. Armbrecht, and J. E. Morley, "Identification of age-dependent changes in expression of senescence-accelerated mouse (SAMP8) hippocampal proteins by expression array analysis," Biochemical and Biophysical Research Communications, vol. 272, no. 3, pp. 657-661, 2000.

[65] J. E. Morley, V. B. Kumar, A. E. Bernardo et al., " $\beta$-Amyloid precursor polypeptide in SAMP8 mice affects learning and memory," Peptides, vol. 21, no. 12, pp. 1761-1767, 2000.

[66] V. B. Kumar, K. Vyas, M. Franko et al., "Molecular cloning, expression, and regulation of hippocampal amyloid precursor protein of senescence accelerated mouse (SAMP8)," Biochemistry and Cell Biology, vol. 79, no. 1, pp. 57-67, 2001.

[67] H. F. Poon, G. Joshi, R. Sultana et al., "Antisense directed at the $\mathrm{A} \beta$ region of APP decreases brain oxidative markers in aged senescence accelerated mice," Brain Research, vol. 1018, no. 1, pp. 86-96, 2004.

[68] H. F. Poon, A. Castegna, S. A. Farr et al., "Quantitative proteomics analysis of specific protein expression and oxidative modification in aged senescence-accelerated-prone 8 mice brain," Neuroscience, vol. 126, no. 4, pp. 915-926, 2004.

[69] J. Del Valle, J. Duran-Vilaregut, G. Manich et al., "Early amyloid accumulation in the hippocampus of SAMP8 mice," Journal of Alzheimer's Disease, vol. 19, no. 4, pp. 1303-1315, 2010.

[70] J. Del Valle, S. Bayod, A. Camins et al., "Dendritic spine abnormalities in hippocampal CA1 pyramidal neurons underlying memory deficits in the SAMP8 mouse model of 
Alzheimer's disease," Journal of Alzheimer's Disease, vol. 32, no. 1, pp. 233-240, 2012.

[71] J. Del Valle, J. Duran-Vilaregut, G. Manich et al., "Cerebral amyloid angiopathy, blood-brain barrier disruption and amyloid accumulation in SAMP8 mice," Neurodegenerative Diseases, vol. 8, no. 6, pp. 421-429, 2011.

[72] C. Pelegrí, A. M. Canudas, J. del Valle et al., "Increased permeability of blood-brain barrier on the hippocampus of a murine model of senescence," Mechanisms of Ageing and Development, vol. 128, no. 9, pp. 522-528, 2007.

[73] J. del Valle, J. Duran-Vilaregut, G. Manich et al., "Timecourse of blood-brain barrier disruption in senescenceaccelerated mouse prone 8 (SAMP8) mice," International Journal of Developmental Neuroscience, vol. 27, no. 1, pp. 47$52,2009$.

[74] G. Manich, C. Mercader, J. Del Valle et al., "Characterization of amyloid- $\beta$ granules in the hippocampus of SAMP8 mice," Journal of Alzheimer's Disease, vol. 25, no. 3, pp. 535-546, 2011.

[75] B. Wu, M. Ueno, M. Onodera et al., "RAGE, LDL receptor, and LRP1 expression in the brains of SAMP8," Neuroscience Letters, vol. 461, no. 2, pp. 100-105, 2009.

[76] S. Oddo, A. Caccamo, L. Tran et al., "Temporal profile of amyloid- $\beta(\mathrm{A} \beta)$ oligomerization in an in vivo model of Alzheimer disease: a link between $\mathrm{A} \beta$ and tau pathology," Journal of Biological Chemistry, vol. 281, no. 3, pp. 15991604, 2006.

[77] D. M. Walsh and D. J. Selkoe, "A $\beta$ oligomers-a decade of discovery," Journal of Neurochemistry, vol. 101, no. 5, pp. 1172-1184, 2007.

[78] W. A. Banks, S. A. Farr, J. E. Morley, K. M. Wolf, V. Geylis, and M. Steinitz, "Anti-amyloid beta protein antibody passage across the blood-brain barrier in the SAMP8 mouse model of Alzheimer's disease: an age-related selective uptake with reversal of learning impairment," Experimental Neurology, vol. 206, no. 2, pp. 248-256, 2007.

[79] Q. Li, H. F. Zhao, Z. F. Zhang et al., "Long-term green tea catechin administration prevents spatial learning and memory impairment in senescence-accelerated mouse prone8 mice by decreasing $A \beta 1-42$ oligomers and upregulating synaptic plasticity-related proteins in the hippocampus," Neuroscience, vol. 163, no. 3, pp. 741-749, 2009.

[80] V. B. Kumar, M. Franko, W. A. Banks et al., "Increase in presenilin 1 (PS1) levels in senescence-accelerated mice (SAMP8) may indirectly impair memory by affecting amyloid precursor protein (APP) processing," Journal of Experimental Biology, vol. 212, no. 4, pp. 494-498, 2009.

[81] J. J. Palop and L. Mucke, "Amyloid- $\beta$-induced neuronal dysfunction in Alzheimer's disease: from synapses toward neural networks," Nature Neuroscience, vol. 13, no. 7, pp. 812-818, 2010.

[82] A. Y. Hsia, E. Masliah, L. McConlogue et al., "Plaqueindependent disruption of neural circuits in Alzheimer's disease mouse models," Proceedings of the National Academy of Sciences of the United States of America, vol. 96, pp. 32283233, 1999.

[83] Y. Yoshiyama, M. Higuchi, B. Zhang et al., "Synapse loss and microglial activation precede tangles in a P301S tauopathy mouse model," Neuron, vol. 53, no. 3, pp. 337-351, 2007.

[84] C. Perez-Cruz, M. W. Nolte, M. M. Van Gaalen et al., "Reduced spine density in specific regions of CA1 pyramidal neurons in two transgenic mouse models of Alzheimer's disease," Journal of Neuroscience, vol. 31, no. 10, pp. 39263934, 2011.
[85] W. A. Banks, S. M. Robinson, S. Verma, and J. E. Morley, "Efflux of human and mouse amyloid $\beta$ proteins 1-40 and 142 from brain: impairment in a mouse model of alzheimer's disease," Neuroscience, vol. 121, no. 2, pp. 487-492, 2003.

[86] M. A. Erickson, M. L. Niehoff, S. A. Farr et al., "Peripheral administration of antisense oligonucleotides targeting the amyloid- $\beta$ protein precursor reverses $\mathrm{A} \beta \mathrm{PP}$ and LRP-1 overexpression in the aged SAMP8 mouse brain," Journal of Alzheimer's Disease, vol. 28, no. 4, pp. 951-960, 2012.

[87] G. H. Chen, Y. J. Wang, X. M. Wang, and J. N. Zhou, "Accelerated senescence prone mouse- 8 shows early onset of deficits in spatial learning and memory in the radial six-arm water maze," Physiology and Behavior, vol. 82, no. 5, pp. 883890, 2004.

[88] X. Wei, Y. Zhang, and J. Zhou, “Alzheimer's disease-related gene expression in the brain of senescence accelerated mouse," Neuroscience Letters, vol. 268, no. 3, pp. 139-142, 1999.

[89] W. A. Banks, S. A. Farr, and J. E. Morley, "Permeability of the blood-brain barrier to albumin and insulin in the young and aged SAMP8 mouse," Journals of Gerontology, vol. 55, no. 12, pp. B601-B606, 2000.

[90] S. Michan and D. Sinclair, "Sirtuins in mammals: insights into their biological function," Biochemical Journal, vol. 404, no. 1, pp. 1-13, 2007.

[91] M. D. Knutson and C. Leeuwenburgh, "Resveratrol and novel potent activators of SIRT1: effects on aging and age-related diseases," Nutrition Reviews, vol. 66, no. 10, pp. 591-596, 2008.

[92] V. Quivy and C. Van Lint, "Regulation at multiple levels of NF- $\kappa \mathrm{B}$-mediated transactivation by protein acetylation," Biochemical Pharmacology, vol. 68, no. 6, pp. 1221-1229, 2004.

[93] W. Qin, T. Yang, L. Ho et al., "Neuronal SIRT1 activation as a novel mechanism underlying the prevention of alzheimer disease amyloid neuropathology by calorie restriction," Journal of Biological Chemistry, vol. 281, no. 31, pp. 21745-21754, 2006.

[94] G. Donmez, D. Wang, D. E. Cohen, and L. Guarente, "SIRT1 suppresses $\beta$-amyloid production by activating the $\alpha$ secretase gene ADAM10," Cell, vol. 142, no. 2, pp. 320-332, 2010.

[95] D. J. Bonda, H. G. Lee, A. Camins et al., "The sirtuin pathway in ageing and Alzheimer disease: mechanistic and therapeutic considerations," The Lancet Neurology, vol. 10, no. 3, pp. 275279, 2011.

[96] S. S. Karuppagounder, J. T. Pinto, H. Xu, H. L. Chen, M. F. Beal, and G. E. Gibson, "Dietary supplementation with resveratrol reduces plaque pathology in a transgenic model of Alzheimer's disease," Neurochemistry International, vol. 54, no. 2, pp. 111-118, 2009.

[97] M. Pallàs, J. G. Pizarro, J. Gutierrez-Cuesta et al., "Modulation of SIRT1 expression in different neurodegenerative models and human pathologies," Neuroscience, vol. 154, no. 4, pp. 1388-1397, 2008.

[98] M. J. Sharps, "Spatial memory in young and elderly adults: category structure of stimulus sets," Psychology and Aging, vol. 6, no. 2, pp. 309-312, 1991.

[99] R. J. Weber, L. T. Brown, and J. K. Weldon, "Cognitive maps of environmental knowledge and preference in nursing home patients," Experimental Aging Research, vol. 4, no. 3, pp. 157$174,1978$.

[100] J. E. Morley, S. A. Farr, and J. F. Flood, "Antibody to amyloid beta protein alleviates impaired acquisition, retention, and 
memory processing in SAMP8 mice," Neurobiology of Learning and Memory, vol. 78, no. 1, pp. 125-138, 2002.

[101] J. F. Flood and J. E. Morley, "Early onset of age-related impairment of aversive and appetitive learning in the SAMP/8 mouse," Journals of Gerontology, vol. 47, no. 2, pp. B52B59, 1992.

[102] J. F. Flood, S. A. Farr, K. Uezu, and J. E. Morley, "The pharmacology of post-trial memory processing in septum," European Journal of Pharmacology, vol. 350, no. 1, pp. 31-38, 1998.

[103] S. Ikegami, S. Shumiya, and H. Kawamura, "Age-related changes in radial-arm maze learning and basal forebrain cholinergic systems in senescence accelerated mice (SAM)," Behavioural Brain Research, vol. 51, no. 1, pp. 15-22, 1992.

[104] H. Cheng, J. Yu, Z. Jiang et al., "Acupuncture improves cognitive deficits and regulates the brain cell proliferation of SAMP8 mice," Neuroscience Letters, vol. 432, no. 2, pp. 111 116, 2008.

[105] J. F. Flood and J. E. Morley, "Age-related changes in footshock avoidance acquisition and retention in senescence accelerated mouse (SAM)," Neurobiology of Aging, vol. 14, no. 2, pp. 153157, 1993.

[106] M. Miyamoto, "Characteristics of age-related behavioral changes in senescence-accelerated Mouse SAMP8 and SAMP10," Experimental Gerontology, vol. 32, no. 1-2, pp. 139-148, 1997.

[107] M. Miyamoto, Y. Kiyota, M. Nishiyama, and A. Nagaoka, "Senescence-accelerated mouse (SAM): age-related reduced anxiety-like behavior in the SAM-P/8 strain," Physiology and Behavior, vol. 51, no. 5, pp. 979-985, 1992.

[108] H. Kasai, M. Matsuzaki, J. Noguchi, N. Yasumatsu, and H. Nakahara, "Structure-stability-function relationships of dendritic spines," Trends in Neurosciences, vol. 26, no. 7, pp. 360-368, 2003.

[109] H. Kasai, M. Fukuda, S. Watanabe, A. Hayashi-Takagi, and J. Noguchi, "Structural dynamics of dendritic spines in memory and cognition," Trends in Neurosciences, vol. 33, no. 3, pp. 121-129, 2010.

[110] J. Bourne and K. M. Harris, "Do thin spines learn to be mushroom spines that remember?" Current Opinion in Neurobiology, vol. 17, no. 3, pp. 381-386, 2007.

[111] F. Madeo, N. Tavernarakis, and G. Kroemer, "Can autophagy promote longevity?" Nature Cell Biology, vol. 12, no. 9, pp. 842-846, 2010.

[112] B. Caballero and A. Coto-Montes, "An insight into the role of autophagy in cell responses in the aging and neurodegenerative brain," Histology and Histopathology, vol. 27, no. 3, pp. 263-275, 2012.

[113] B. A. McCray and J. P. Taylor, "The role of autophagy in agerelated neurodegeneration," NeuroSignals, vol. 16, no. 1, pp. 75-84, 2007.

[114] T. Shintani and D. J. Klionsky, "Autophagy in health and disease: a double-edged sword," Science, vol. 306, no. 5698, pp. 990-995, 2004.

[115] A. Cichanover, "Intracellular protein degradation: from a vague idea thru the lysosome and the ubiquitin-proteasome system and onto human diseases and drug targeting," Cell Death and Differentiation, vol. 12, no. 9, pp. 1178-1190, 2005.

[116] B. Levine and D. J. Klionsky, "Development by selfdigestion: molecular mechanisms and biological functions of autophagy," Developmental Cell, vol. 6, no. 4, pp. 463-477, 2004.

[117] B. Caballero, I. Vega-Naredo, V. Sierra et al., "Autophagy upregulation and loss of NF- $\kappa \mathrm{B}$ in oxidative stress-related immunodeficient SAMP8 mice," Mechanisms of Ageing and Development, vol. 130, no. 11-12, pp. 722-730, 2009.

[118] Q. Ma, J. Qiang, P. Gu, Y. Wang, Y. Geng, and M. Wang, "Age-related autophagy alterations in the brain of senescence accelerated mouse prone 8 (SAMP8) mice," Experimental Gerontology, vol. 46, no. 7, pp. 533-541, 2011.

[119] J. Menardo, Y. Tang, and S. Ladrech, "Oxidative stress, inflammation, and autophagic stress as the key mechanisms of premature age-related hearing loss in SAMP8 mouse cochlea," Antioxidant and Redox Signaling, vol. 16, no. 3, pp. 263-274, 2012.

[120] T. Nishikawa, J. A. Takahashi, Y. Fujibayashi et al., "An early stage mechanism of the age-associated mitochondrial dysfunction in the brain of SAMP8 mice; an age-associated neurodegeneration animal model," Neuroscience Letters, vol. 254, no. 2, pp. 69-72, 1998.

[121] P. H. Reddy and M. F. Beal, "Amyloid beta, mitochondrial dysfunction and synaptic damage: implications for cognitive decline in aging and Alzheimer's disease," Trends in Molecular Medicine, vol. 14, no. 2, pp. 45-53, 2008.

[122] I. G. Onyango, J. Lu, M. Rodova, E. Lezi, A. B. Crafter, and R. H. Swerdlow, "Regulation of neuron mitochondrial biogenesis and relevance to brain health," Biochimica et Biophysica Acta, vol. 1802, no. 1, pp. 228-234, 2010.

[123] M. I. Rodríguez, G. Escames, L. C. López et al., "Improved mitochondrial function and increased life span after chronic melatonin treatment in senescent prone mice," Experimental Gerontology, vol. 43, no. 8, pp. 749-756, 2008.

[124] M. Carretero, G. Escames, L. C. López et al., "Long-term melatonin administration protects brain mitochondria from aging," Journal of Pineal Research, vol. 47, no. 2, pp. 192-200, 2009.

[125] J. Xu, C. Shi, Q. Li, J. Wu, E. L. Forster, and D. T. Yew, "Mitochondrial dysfunction in platelets and hippocampi of senescence-accelerated mice," Journal of Bioenergetics and Biomembranes, vol. 39, no. 2, pp. 195-202, 2007.

[126] F. Tian, T. J. Tong, Z. Y. Zhang, M. A. McNutt, and X. W. Liu, "Age-dependent down-regulation of mitochondrial 8oxoguanine dna glycosylase in sam-p/8 mouse brain and its effect on brain aging," Rejuvenation Research, vol. 12, no. 3, pp. 209-215, 2009.

[127] T. Nishikawa, J. A. Takahashi, Y. Fujibayashi et al., "An early stage mechanism of the age-associated mitochondrial dysfunction in the brain of SAMP8 mice; an age-associated neurodegeneration animal model," Neuroscience Letters, vol. 254, no. 2, pp. 69-72, 1998.

[128] R. Rodríguez-Calvo, M. Jové, T. Coll et al., "PGC-1 $\beta$ down-regulation is associated with reduced $\mathrm{ERR} \alpha$ activity and MCAD expression in skeletal muscle of senescenceaccelerated mice," Journals of Gerontology, vol. 61, no. 8, pp. 773-780, 2006.

[129] A. Salminen, K. Kaarniranta, A. Haapasalo, H. Soininen, and M. Hiltunen, "AMP-activated protein kinase: a potential player in Alzheimer's disease," Journal of Neurochemistry, vol. 118, no. 4, pp. 460-474, 2011.

[130] V. Vingtdeux, P. Davies, D. W. Dickson, and P. Marambaud, "AMPK is abnormally activated in tangle-and pretangle-bearing neurons in Alzheimer's disease and other tauopathies," Acta Neuropathologica, vol. 121, no. 3, pp. 337349, 2011.

[131] J. S. Won, Y. B. Im, J. Kim, A. K. Singh, and I. Singh, "Involvement of AMP-activated-protein-kinase (AMPK) in neuronal amyloidogenesis," Biochemical and Biophysical Research Communications, vol. 399, no. 4, pp. 487-491, 2010. 
[132] J. J. Pei, C. Björkdahl, H. Zhang, X. Zhou, and B. Winblad, "p70 S6 kinase and tau in Alzheimer's disease," Journal of Alzheimer's Disease, vol. 14, no. 4, pp. 385-392, 2008.

[133] J. J. Pei and J. Hugon, "mTOR-dependent signalling in Alzheimer's disease," Journal of Cellular and Molecular Medicine, vol. 12, no. 6B, pp. 2525-2532, 2008.

[134] B. Dasgupta and J. Milbrandt, "Resveratrol stimulates AMP kinase activity in neurons," Proceedings of the National Academy of Sciences of the United States of America, vol. 104, no. 17, pp. 7217-7222, 2007.

[135] N. L. Price, A. P. Gomes, A. J. Y. Ling et al., "SIRT1 is required for AMPK activation and the beneficial effects of RSV on mitochondrial function," Cell Metabolism, vol. 15, no. 5, pp. 675-690, 2012.

[136] S. J. Park, F. Ahmad, A. Philp et al., "RSV ameliorates aging-related metabolic phenotypes by inhibiting cAMP phosphodiesterases," Cell, vol. 148, no. 3, pp. 421-433, 2012.

[137] E. Morselli, L. Galluzzi, O. Kepp et al., "Autophagy mediates pharmacological lifespan extension by spermidine and resveratrol," Aging, vol. 1, no. 12, pp. 961-970, 2009.

[138] E. Morselli, M. C. Maiuri, M. Markaki et al., "Caloric restriction and resveratrol promote longevity through the sirtuin-1-dependent induction of autophagy," Cell Death and Disease, vol. 1, no. 1, article e10, 2010.

[139] H. Chen and D. C. Chan, "Mitochondrial dynamics-fusion, fission, movement, and mitophagy-in neurodegenerative diseases," Human molecular genetics, vol. 18, no. 2, pp. R169R176, 2009.

[140] M. J. Barsoum, H. Yuan, A. A. Gerencser et al., "Nitric oxideinduced mitochondrial fission is regulated by dynaminrelated GTPases in neurons," EMBO Journal, vol. 25, no. 16, pp. 3900-3911, 2006.

[141] S. Chang, T. R. Ma, R. D. Miranda, M. E. Balestra, R. W. Mahley, and Y. Huang, "Lipid- and receptor-binding regions of apolipoprotein E4 fragments act in concert to cause mitochondrial dysfunction and neurotoxicity," Proceedings of the National Academy of Sciences of the United States of America, vol. 102, no. 51, pp. 18694-18699, 2005.

[142] R. K. Dagda, S. J. Cherra, S. M. Kulich, A. Tandon, D. Park, and C. T. Chu, "Loss of PINK1 function promotes mitophagy through effects on oxidative stress and mitochondrial fission," Journal of Biological Chemistry, vol. 284, no. 20, pp. 13843-13855, 2009.

[143] X. Wang, B. Su, L. Zheng, G. Perry, M. A. Smith, and $\mathrm{X}$. Zhu, "The role of abnormal mitochondrial dynamics in the pathogenesis of Alzheimer's disease," Journal of Neurochemistry, vol. 109, supplement 1, pp. 153-159, 2009. 

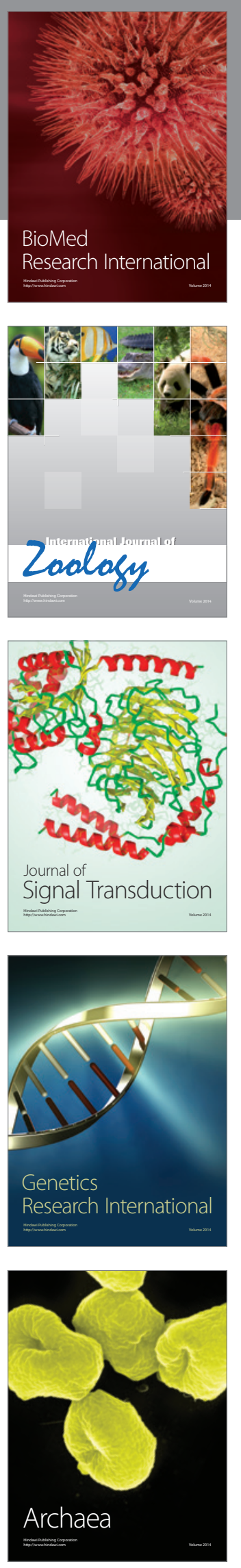
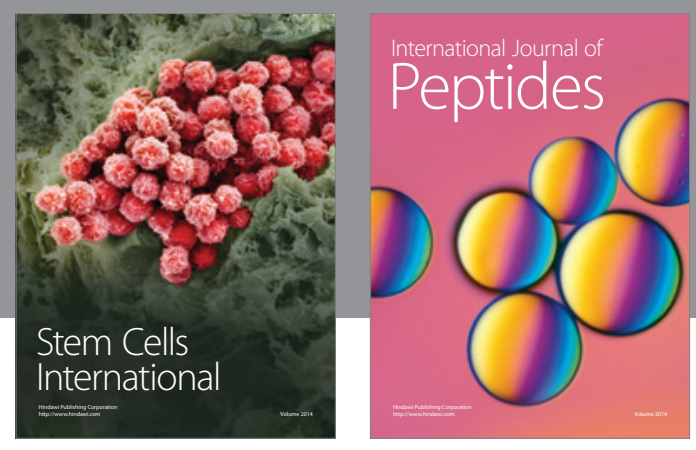

Submit your manuscripts at

http://www.hindawi.com
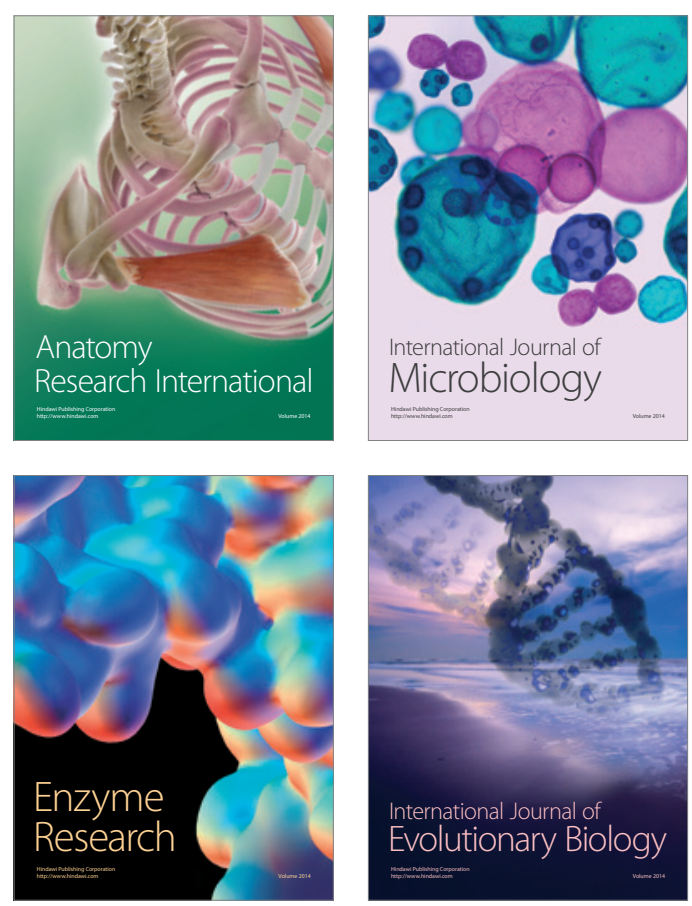
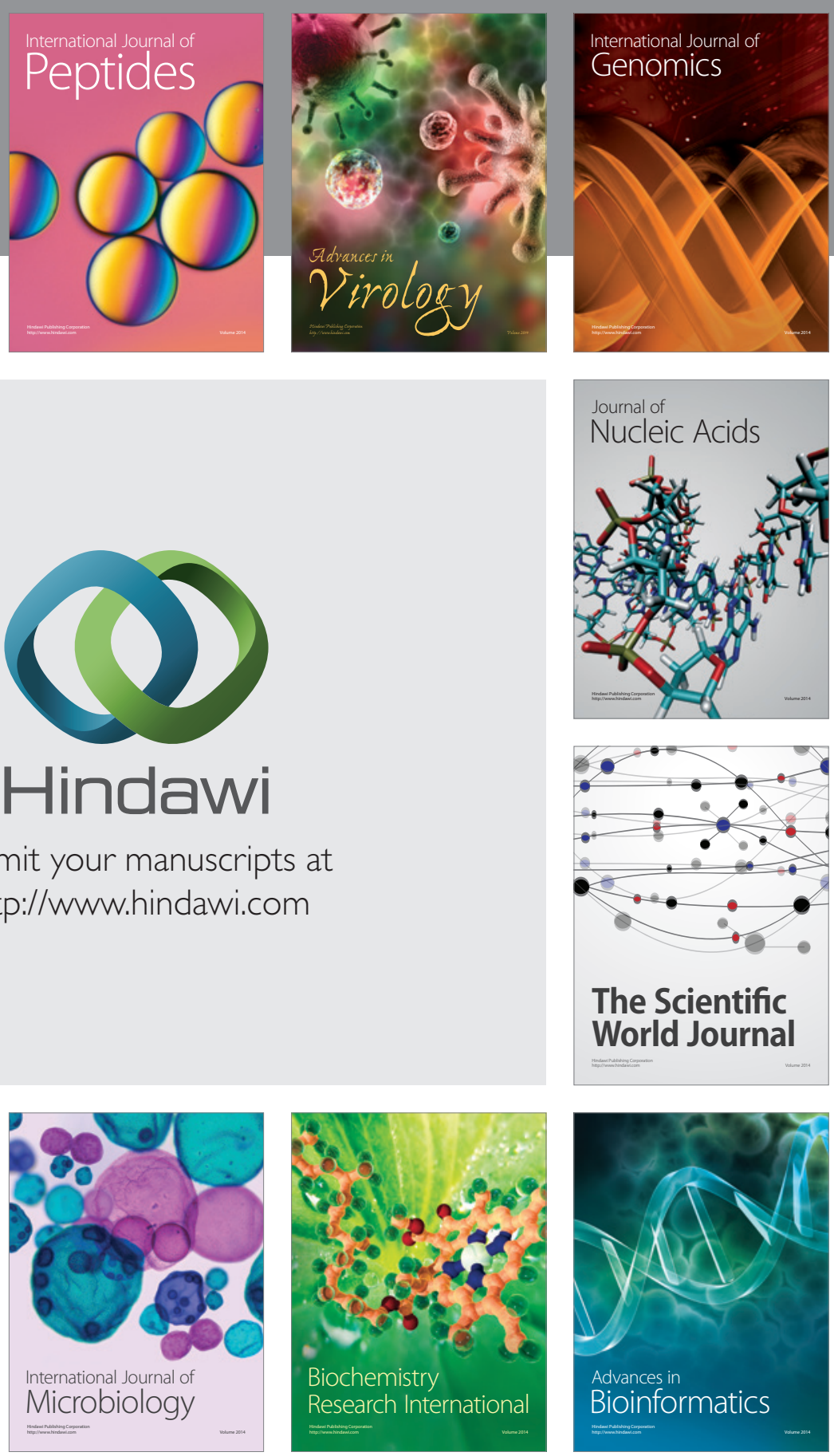

The Scientific World Journal
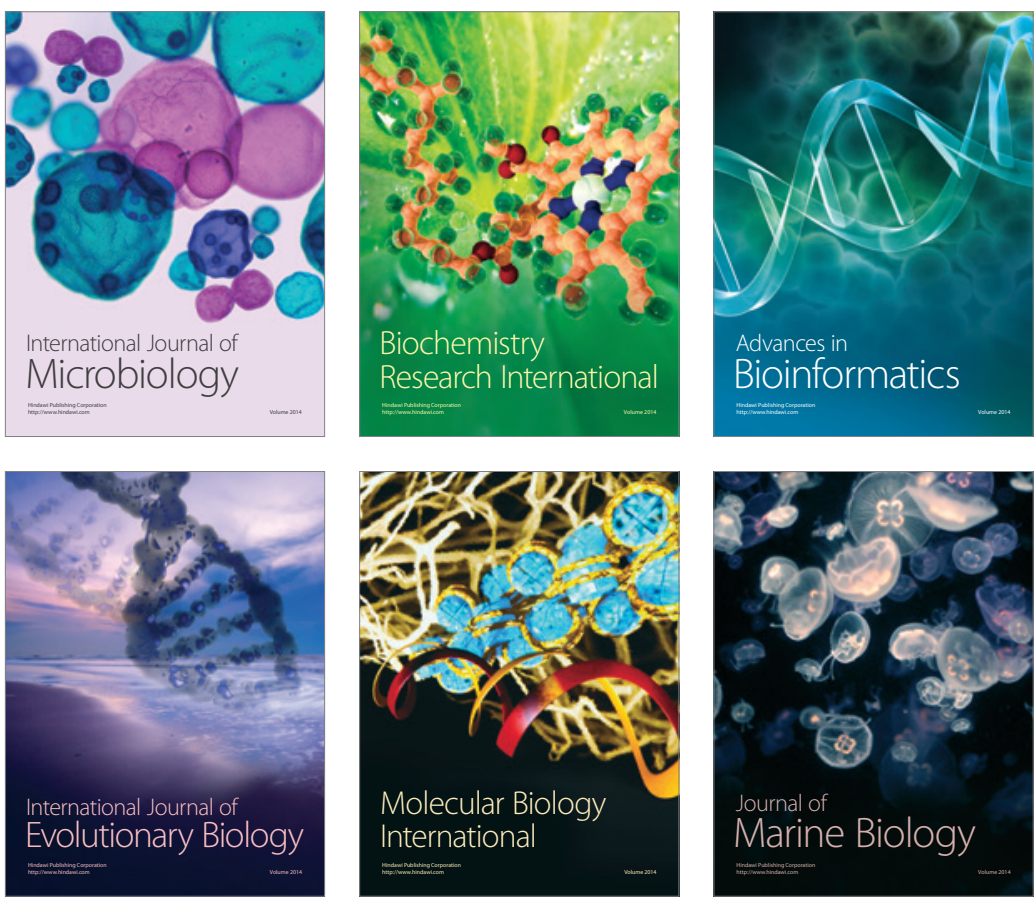